\title{
Epoxy/PCL nanocomposites: Effect of layered silicate on structure and behavior
}

\author{
J. Rotrekl, L. Matějka, L. Kaprálková, A. Zhigunov, J. Hromádková, I. Kelnar* \\ Institute of Macromolecular Chemistry, Academy of Sciences of the Czech Republic, Heyrovsky Sq. 2, 16206 Prague, \\ Czech Republic
}

Received 22 May 2012; accepted in revised form 19 July 2012

\begin{abstract}
The effect of clay-induced morphological transitions on the structure formed in the course of reactively induced phase separation (RIPS) and its impact on the properties of epoxy/polycaprolactone (PCL) nanocomposites were studied. The effect of organophilized montmorillonite on the behavior of epoxy containing 5-30\% PCL was strongly dependent on the epoxy/PCL system composition. With a supercritical 20\% PCL content, the increasing amounts of clay led to changes in the morphology that produced phase inversion, causing radical changes in the mechanical behavior. The main effect of the clay, which was located preferentially in the epoxy, was to influence the significant dynamic asymmetry (and thus the phase behavior). The simultaneous pinning effect of the clay on the phase separation changed the composition and parameters of the coexisting phases. The evaluation of the structure-properties relationship indicated the significant potential for nanoclays to control the behavior of thermoplastic- modified epoxy systems.
\end{abstract}

Keywords: nanocomposites, epoxy, mechanical properties, microstructure, phase separation

\section{Introduction}

The use of engineering thermoplastic polymers [15] to enhance and balance the mechanical properties of epoxy resins has been investigated as an alternative to liquid rubber toughening [6] since the 1980s. The application of engineering thermoplastics like polyether ether ketone (PEEK) [1], polyether sulphone (PES) [2], polyether imide (PEI) [3, 4], and polybutylene terephatlate (PBT) [5] can enhance the toughness of epoxies with less marked reduction of their other properties. The primary shortcoming is the increase in viscosity that limits the content of the modifier. An increasing number of studies have indicated not only that nanofillers (NF) can compensate for the stiffness reduction of impact-modified polymeric systems but also that a suitable combination of NF and a polymeric modifier can also provide a synergistic effect (e.g., further increasing the material toughness) [7-16]. The enhanced efficiency of impact modifiers allows their content to be reduced. This effect was observed in both immiscible thermoplastic systems [7-9] and epoxies with two phase structures formed by the reaction-induced phase separation (RIPS) [10] of a modifier dissolved in an uncured resin. The enhanced mechanical performance of epoxy systems was mostly observed in liquid rubbers and clays [11-13] and in combinations of thermoplastics (PEEK, PEI, PES, ABS) and clays [14-20]. The synergistic effect of the nanofiller consists in its complex effect on the multiphase system by reinforcement, leading also to a change in the component parameter profile combined with a significant influence on the structure and parameters of the interface. The NF influences the structure by affecting the dynamic phase behavior in the case of immiscible thermoplastics [7-9]

\footnotetext{
${ }^{*}$ Corresponding author, e-mail: kelnar@imc.cas.cz

(c) BME-PT
} 
and the phase separation (including RIPS) that occurs in thermosets. In both cases, the change of morphology type and dimension, including the formation of complex structures, is accompanied by an influence on the interface and crystallinity parameters [19].

The effect of inorganic particles on the structure of multiphase polymers has been demonstrated in both experimental and theoretical studies [21-24]. Generally, fillers can support the initiation of phase separation [24-26] (e.g., by composition [25] fluctuations due to preferential wetting of one polymer phase on the filler surface [26]), and they also have a pinning effect during the subsequent separation because they increase the viscosity, blocking mass transfer [23, 27-29] in the system. Especially in the case of RIPS, separation can also be influenced by NF-induced effects on the crosslinking reaction kinetics [30].

The combination of a low $T_{\mathrm{g}}$ and low viscosity epoxy with a dissolved high $T_{\mathrm{g}}$ and high molecular weight thermoplastic polymer represents a system with significant dynamic asymmetry (i.e., a system in which the phase separation is strongly influenced by viscoelastic effects) [31-34]. As a result, relatively unexpected complex phase separations occur, which are strongly time and temperature dependent. The variation in the component molecular weight can be an effective tool to generate favorable structures (e.g., fine particles for elastomers and co-continuous structures for thermoplastic tougheners in epoxy). The advantage of reactive systems is that these structures may be fixed by vitrification and gelation. The comprehensive influence of nanofillers on polymers offers significant potential for nanofiller (NF) to affect the viscoelastic phase separation. This possibility has been demonstrated in several studies [14-16]. Strong NF effects on the epoxy/ PEI system were shown by Peng and cooworkers $[14,16]$, and the effect of attapulgite on the structure of the epoxy/ PES system was demonstrated by Zhao et al. [35].

The existing studies of epoxy and thermoplastics have focused only on one modifier concentration or a limited composition range, and some lack descriptions of the effects of NF on the structure or fail to evaluate the mechanical behavior.

Based on our results indicating the importance of montmorillonite (MMT) content in epoxy and liquid rubber [11,12], this study focuses on a more detailed description of the relationship between the structure and properties of epoxy containing 5-30\% PCL. The reason for the choice of semicrystalline PCL with relatively low mechanical behavior is the welldescribed phase behavior [40-42] of epoxy/PCL systems and the reported potential to upgrade epoxy $[36,37]$. Moreover, in the selected Diglycidyl ether of bisphenol A/diaminodiphenyl sulfone (DGEBA/ DDS) system, the phase separation proceeds above the melting point of PCL. A further advantage of this semi-model system is the relatively easy dissolution of PCL in epoxy (Lower critical solution temperature - LCST) and the fair phase contrast in optical microscopy, which is necessary for a more comprehensive study of the effect of MMT on RIPS, which would constitute a continuation of this work.

\section{Experimental \\ 2.1. Materials}

Cloisite C30 B (MMT modified with methyl tallow bis(2-hydroxyethyl) quaternary ammonium chloride) was obtained from Southern Clay Products, Inc. (Gonzales, Texas, USA). Polycaprolactone (PCL) m.w. 40000 was obtained from Perstorp (Perstorp, Sweden). Diglycidyl ether of bisphenol A (DGEBA)based epoxy resin Epilox A19-02 (epoxy equivalent weight 185-200 g, m.w. 396 g/mol) Leuna-Harze $\mathrm{GmbH}$ (Leuna, Germany), amine hardener diaminodiphenyl sulfone (DDS) Aldrich ( St. Louis, Missouri, USA).

\subsection{Preparation of epoxy hybrid composites}

The epoxy nanocomposites were prepared using a rotary mixer with an evacuated chamber. Clay and PCL were mixed with epoxy resin at $130^{\circ} \mathrm{C}$ for $60 \mathrm{~min}$. Then the curing agent was added, and the mixing continued for $10 \mathrm{~min}$ at the same temperature. Test specimens $(1.5 \mathrm{~mm}$ thick dog-bone with the working part length of $40 \mathrm{~mm}$ and width of $4 \mathrm{~mm}$ and unnotched Charpy bars $80 \times 10 \times 4 \mathrm{~mm}^{3}$ ) were prepared by casting the sample into a steel mold and curing at $170^{\circ} \mathrm{C}$ for 4 hours.

\subsection{Testing}

The tensile strength tests were carried out at $22^{\circ} \mathrm{C}$ using an Instron 5800 apparatus at a crosshead speed of $1 \mathrm{~mm} / \mathrm{min}$. At least eight specimens were tested for each sample. The stress at break $\left(\sigma_{\mathrm{B}}\right.$, vari- 
ation coefficient $<2 \%$ ) and Young's modulus $(E$, variation coefficient $<6 \%$ ) were evaluated. The impact strength was measured using a Zwick hammer (Charpy) with an energy of $4 \mathrm{~J}$ (variation coefficient $<11 \%$ ). The reported values are the averages of ten measurements.

Dynamic mechanical analysis (DMA) was performed with an ARES apparatus (Rheometric Scientific, Piscataway, NJ). $T_{\mathrm{g}}$ was determined from the maximum of the loss modulus $E^{\prime \prime}$, which was measured as a function of temperature at a frequency of $1 \mathrm{~Hz}$. Chemorheological experiments to characterize the time to gel point during curing at $170^{\circ} \mathrm{C}$ were conducted in the parallel-plate geometry using oscillatory shear deformation at a frequency of $6.28 \mathrm{rad} / \mathrm{s}$ $(1 \mathrm{~Hz})$ using the same equipment.

\subsection{Morphological observations}

The phase structure of the cryofractured samples was observed using scanning electron microscopy (SEM). The PCL phase was etched with tetrahydrofuran for $1 \mathrm{~h}$. The size of the dispersed particles was evaluated from the micrographs (from 5 representative pictures containing approximately 100 particles) using a Mini Mop image analyzer (Kontron Co., Germany).

For transmission electron microscopy (TEM), ultrathin $(60 \mathrm{~nm})$ sections were cut using an Ultracut UCT (Leica) ultramicrotome. Wide-angle X-ray diffraction (WAXS) patterns were obtained with an HZG/4A powder diffractometer (Freiberger Präzisionsmechanik GmbH, Germany) and monochromatic $\mathrm{CuK} \alpha$ radiation. The cloud point was determined from light transmission measurements.

\section{Results and discussion}

In this work, we have observed the effect of clay on phase separation during the formation of the DGEBA/DDS/PCL nanocomposite, as well as its final structure and mechanical properties.

\subsection{Effect of clay on $T_{\mathrm{g}}$}

The phase separation of the system was characterized by changes in the $T_{\mathrm{g}}$ of the epoxy because the DMA test used to determine this value does not allow the $T_{\mathrm{g}}$ of PCL to be evaluated (not shown) at $\sim-50^{\circ} \mathrm{C}$ because of the dominance of the interfering secondary sub- $T_{\mathrm{g}}$ transition in the epoxy matrix.
Table 1. Effect of clay on glass transition temperature of epoxy phase and its dependence on PCL content

\begin{tabular}{|c|c|c|c|c|}
\hline \multirow{2}{*}{$\begin{array}{c}\text { PCL } \\
\text { content } \\
{[\mathbf{w t} \%]}\end{array}$} & \multicolumn{4}{|c|}{ C30 content [wt\%] } \\
\cline { 2 - 5 } & $\mathbf{0}$ & $\mathbf{0 . 5}$ & $\mathbf{1 . 5}$ & $\mathbf{3}$ \\
\hline 0 & 202.0 & 200.0 & 199.5 & 198.5 \\
\hline 5 & 198.0 & 195.0 & 194.0 & 192.0 \\
\hline 10 & 197.0 & 194.0 & 193.0 & 183.0 \\
\hline 15 & 193.6 & 191.0 & 183.0 & 173.0 \\
\hline 20 & 191.6 & 181.0 & 172.0 & 161.0 \\
\hline 30 & 179.0 & - & 170.0 & 160.0 \\
\hline
\end{tabular}

The results in Table 1 suggest that a decrease in the glass transition temperature $\left(T_{\mathrm{g}}\right)$ of the epoxy phase occurs at all compositions of epoxy/PCL and that the reduction is more significant as the clay content increases. At the same time, Table 1 clearly shows that the clay also decreases the $T_{\mathrm{g}}$ of neat epoxy. Generally, nanofillers influence the $T_{\mathrm{g}}$ of polymer matrices by two contradictory effects $[38,39]$ : reduction of the chain mobility by interaction with the rigid nanofiller and (b) increase of the free volume because of the presence of the nanofiller and the loosened molecular packing of the chains. In the case of the rigid DGEBA-DDS network, the effect of the increased free volume dominates, leading to a decrease in the $T_{\mathrm{g}}$.

Table 1 also shows that the decrease in $T_{\mathrm{g}}$ is more significant for all PCL-containing nanocomposites than the MMT-induced decrease in the $T_{\mathrm{g}}$ of the single epoxy matrix. This result indicates that the extent of the phase separation (and the content of PCL dissolved in the epoxy phase due) is reduced because of the pinning effect [23] of the clay. Clearly, the pinning effect of clay (which occurs for all PCL content levels) is more apparent at higher PCL contents because of the greater mass transfer and viscosity of the system.

\subsection{Effect of clay on structure}

The results shown in Figures 1-5 indicate that the clay-induced structural transformations are strongly dependent on the PCL content.

In the case of subcritical [40, 41] (5 and $10 \mathrm{wt} \%)$ PCL content, SEM observation (Figures 1 and 2) shows a structure that consists of spherical PCL inclusions in an epoxy rich matrix. The increased clay content, which is preferentially localized in the epoxy (as indicated by TEM, not shown), has an unexpected 


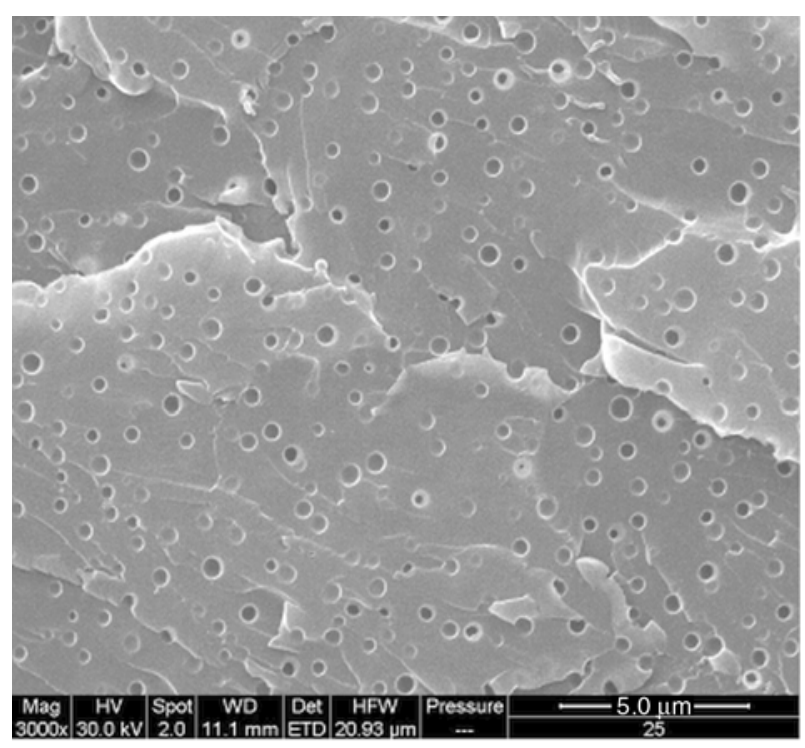

a)

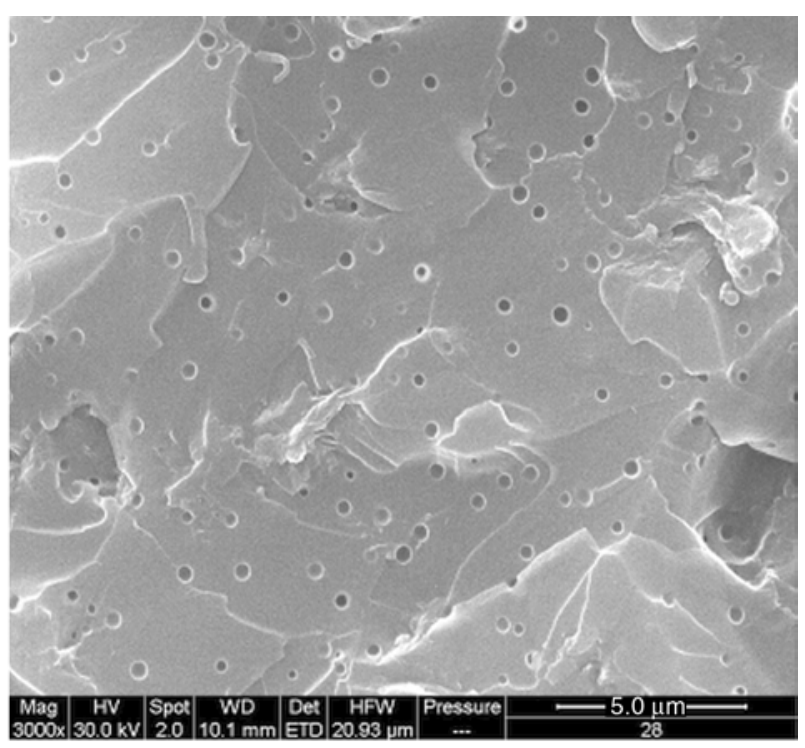

b)

Figure 1. SEM image of epoxy/PCL $95 / 5(\mathrm{w} / \mathrm{w})$ containing (a) $0 \%$ clay (b) $3 \%$ clay

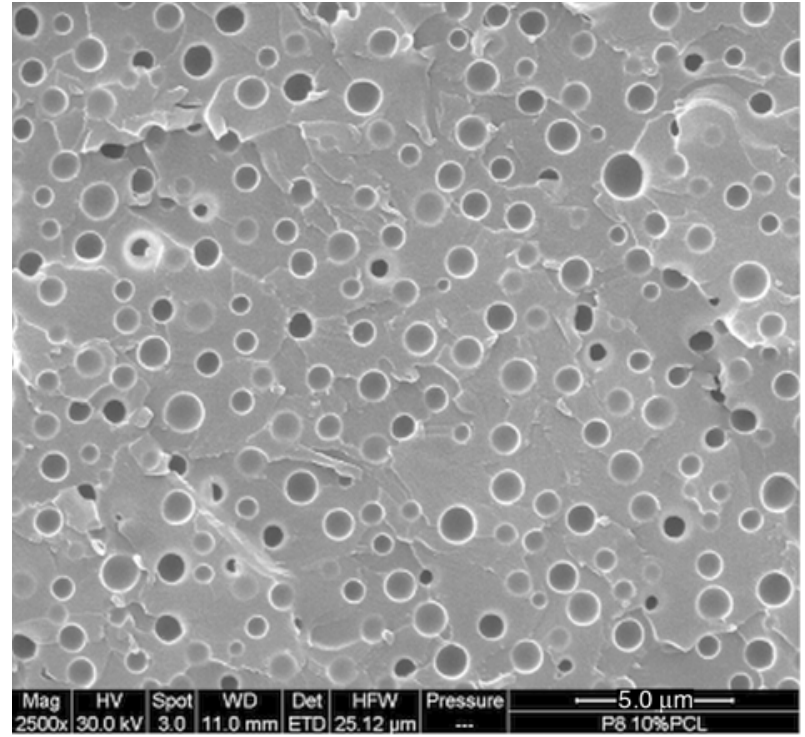

a)

Figure 2. SEM image of 90/10 (a) $0 \%$ clay (b) $3 \%$ clay

effect on the structure. Figure 1 clearly shows that the increased clay content does not affect the particle size in the 95/5 epoxy/PCL system, which is approximately $500 \mathrm{~nm}$ in all cases. Instead, it leads to a reduction in the number of particles and a corresponding enlargement of the interparticle distance. This result seems to be a consequence of the pinning effect of the clay, causing a less-complete phase separation, as indicated by the lower $T_{\mathrm{g}}$ of the epoxy phase (Table 1). Surprisingly, the number of particles decreases, in spite of the expected higher nucleation of the phase separation [25] caused by the presence of clay.

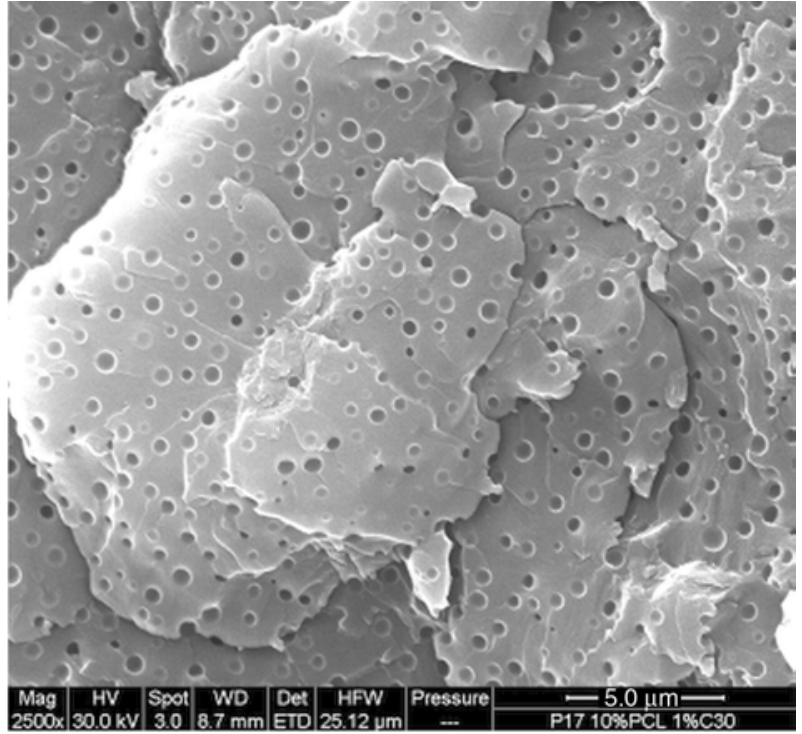

b)

At a 90/10 epoxy/PCL composition, a marked decrease in the size of the PCL inclusions (Figure $2 \mathrm{a}$ ) with $0.5 \%$ clay content was observed, but there was no further effect of the increasing clay content on the size. This result indicates that the dominant pinning effect of the clay with its initial low content is balanced by other clay-induced effects, supporting particle growth with increasing clay content. These effects include clay nucleation [25], which leads to an earlier onset of phase separation [36] at lower conversion and viscosity, as well as a longer interval between the onset of phase separation and gelation [11]. 


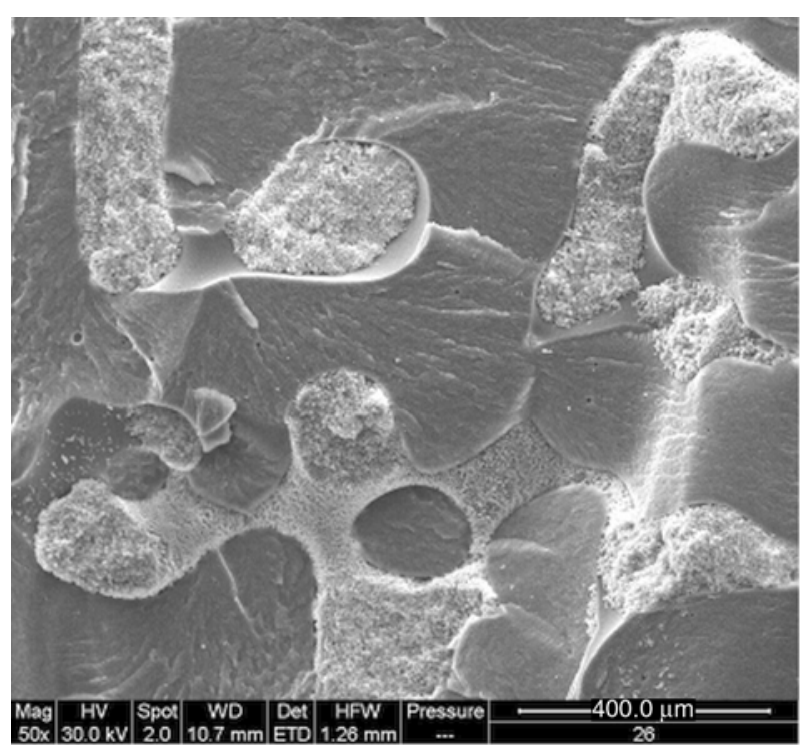

a)

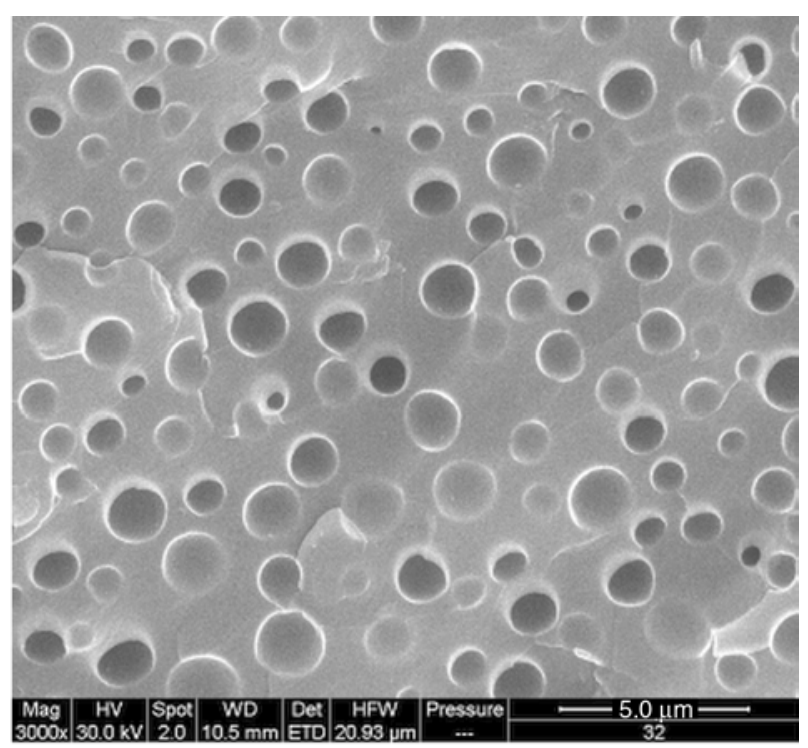

b)

Figure 3. SEM image of $85 / 15$ epoxy/PCL (w/w) with (a) $0 \%$ clay (b) $0.5 \%$ clay

These results represent a difference from epoxy/liquid rubber/clay systems $[11,12]$, in which an increase in particle size was found. This difference can be explained by the expected lower significance of the pinning effect of clay on the phase separation of the modifier as a result of the significantly lower molecular weight (i.e., in the system with the less significant asymmetry).

At supercritical (>12\%) PCL content, the effect of the clay on the morphology is highly significant.

In the case of 85/15 epoxy/PCL without clay, SEM observation (Figure 3 ) shows a relatively rough bicontinuous structure that contains subinclusions of the second phase formed by the secondary phase separation. The PCL-rich phase contains relatively large epoxy globules $(<10 \mu \mathrm{m})$, whereas the PCL inclusions in the epoxy are finer $(<2 \mu \mathrm{m})$.

This structure quickly changes to that of continuous epoxy containing relatively fine PCL inclusions $(\sim 1 \mu \mathrm{m}$ average size) at $0.5 \%$ clay addition. The PCL particles are further refined by the addition of greater clay contents because the larger amount of clay dispersed in the epoxy phase produces a more pronounced change in the dynamic asymmetry. This trend causes an earlier disruption of the initial (finer) bicontinuous structure [34], forming smaller particles whose growth is limited by the increased pinning effect of the clay.

The most significant structural transformation was found for the $80 / 20$ system. The original structure, which had a continuous PCL-rich phase containing approximately $\sim 20 \mu \mathrm{m}$ epoxy-rich particles (Figure 4a), is transformed to an epoxy-rich matrix with fine PCL-rich inclusions when the clay content is greater than $1.5 \%$ MMT (Figure 4c) (i.e., the clay causes a phase inversion). The size of the PCL inclusions further diminishes at 3\% clay (not shown). In the cases of 0.5 and $1 \%$ C30 clay content, rough bicontinuous structures (Figure 4b) with subinclusions of the second phase were observed (approximately corresponding to the $85 / 15$ system without clay in Figure 3a). The reason for this transformation is the lower mobility (higher viscosity) of the epoxy phase due to clay, supporting its continuity. The course of the structure changes with increasing clay content (Figure 4) resembles the time-evolution of the phase separation in an analogous system with a significant dynamic asymmetry caused only by the crosslinking of epoxy [40], but the sequence proceeds in the opposite order. In the case of the most complete separation without clay (Figure 4a), the structure corresponds to the initial stage of the phase separation evolution, [40] whereas in presence of clay and thus hindered separation, 'final' phase inverted structure occurs. As a result, this transformation of the structure by clay cannot be explained by mere 'freezing' [14] of the course of RIPS in the earlier stage.

Consequently, it is clear that the clay changes the phase diagram (position of critical point) of this low critical solution temperature (LCST) system with significant dynamical asymmetry because it remark- 


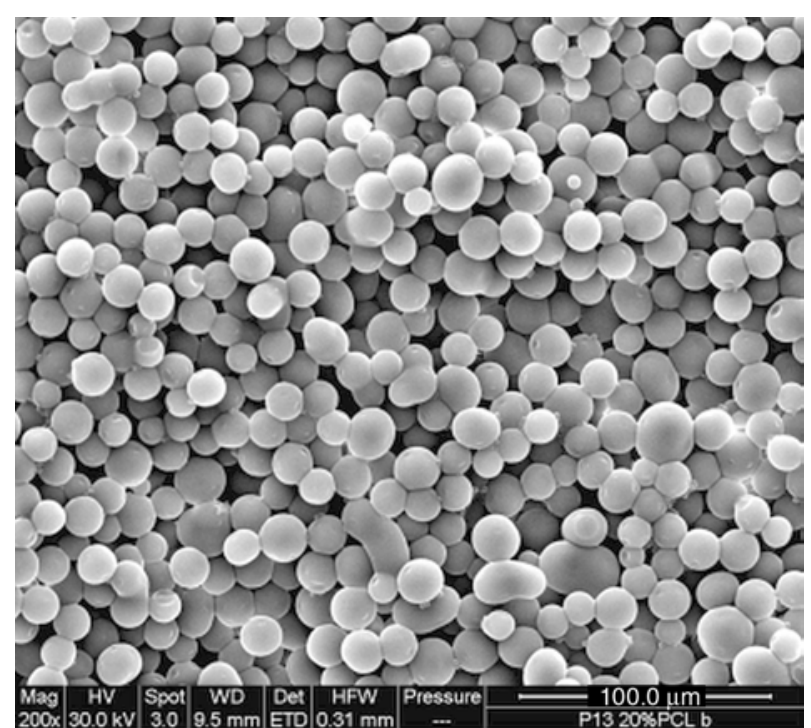

a)

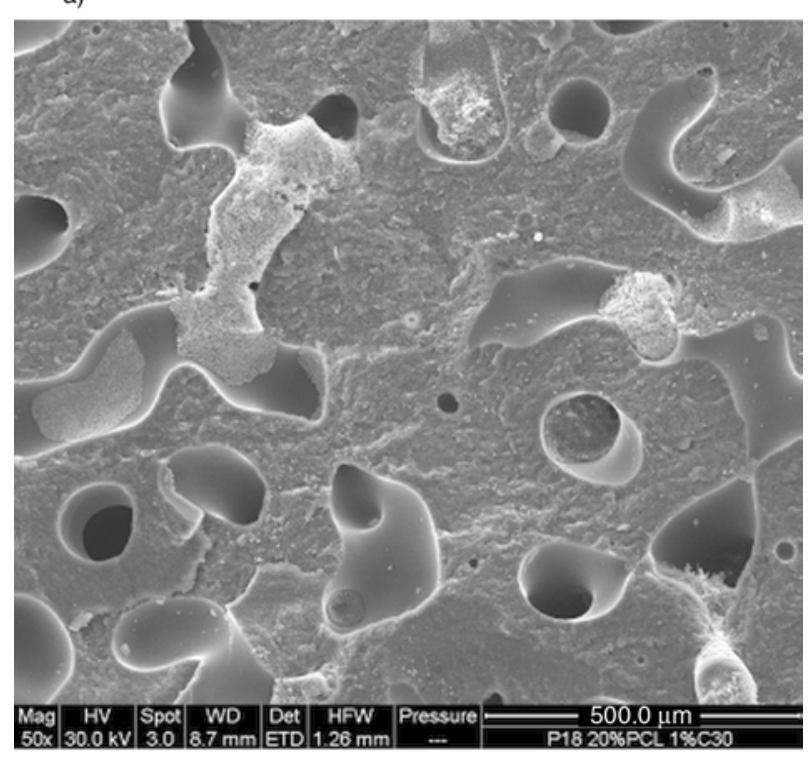

b)

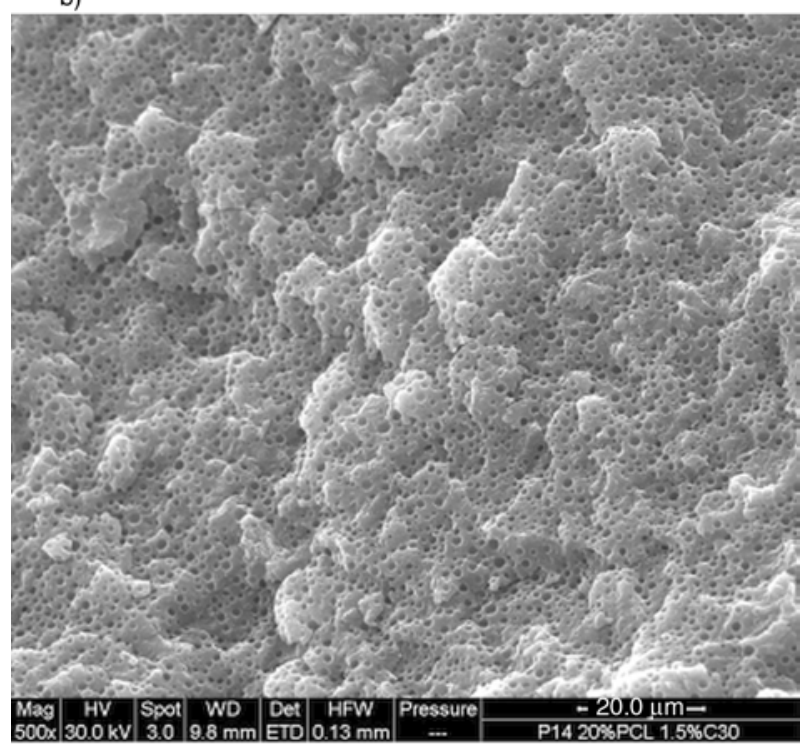

c)

Figure 4. SEM image of $80 / 20$ epoxy/PCL (w/w) with (a) $0 \%$ clay (b) $1 \%$ clay (c) $1.5 \%$ clay

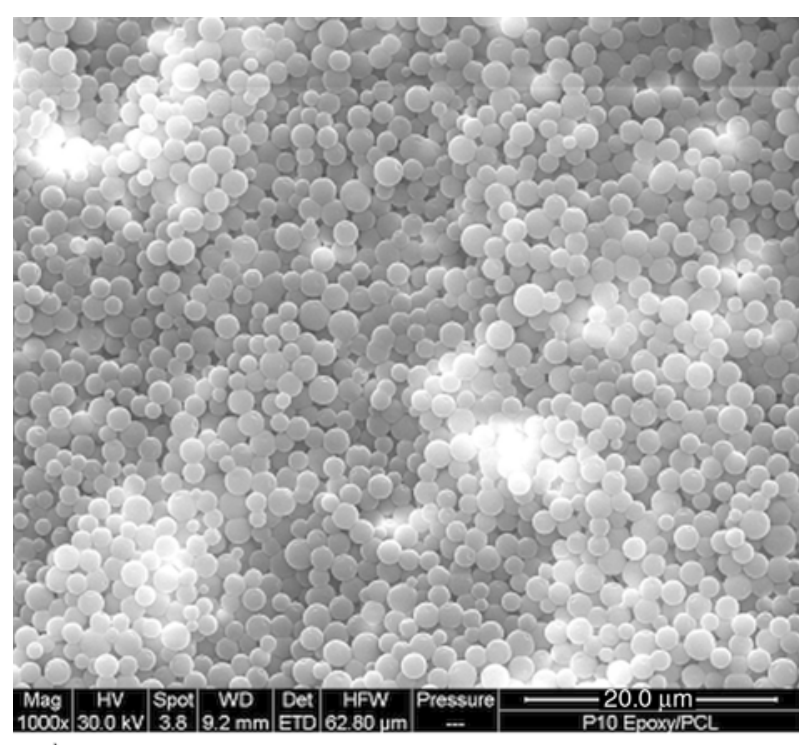

a)

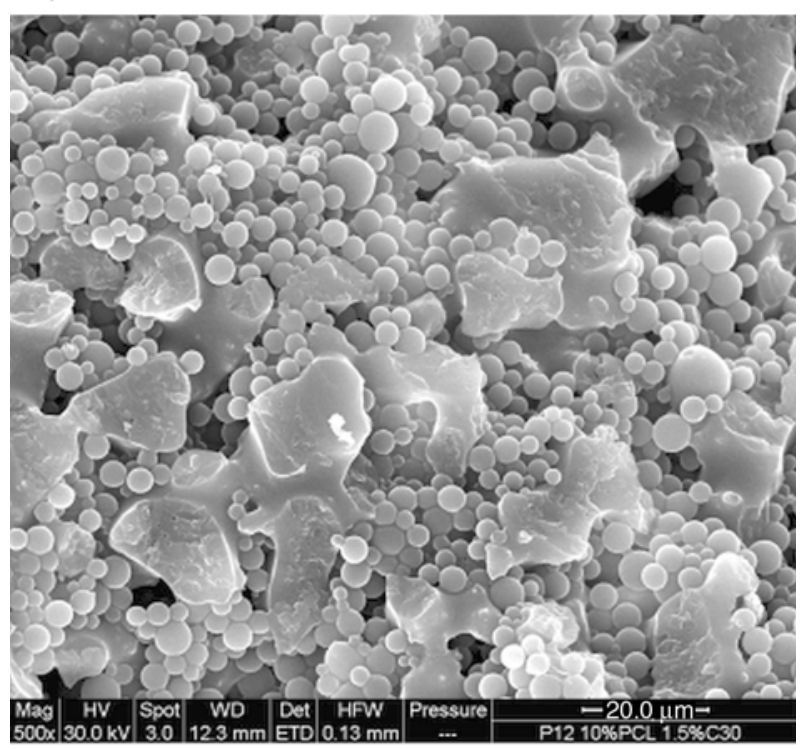

b)

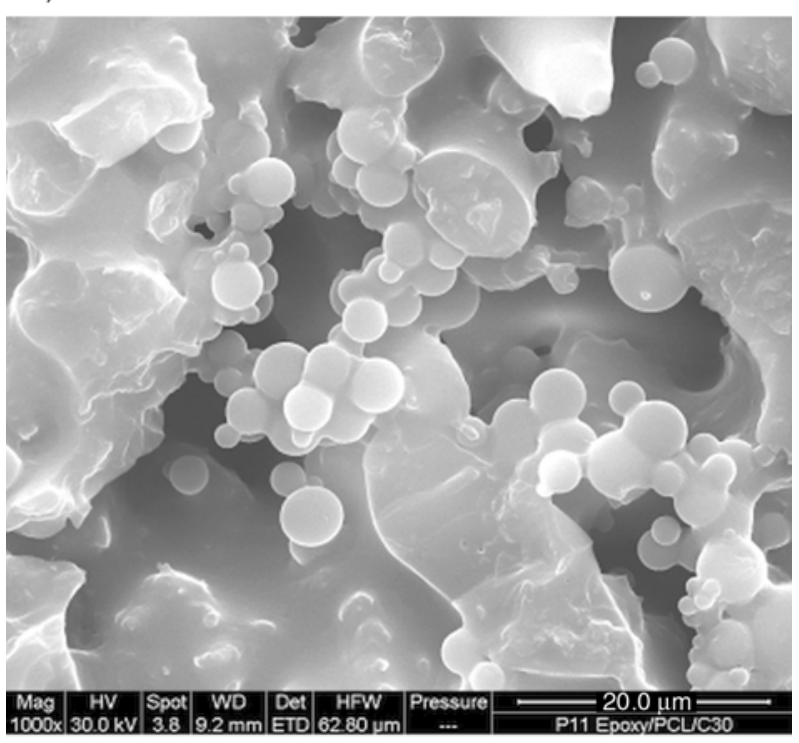

c)

Figure 5. SEM image of 70/30\% epoxy/PCL (w/w) (a) $0 \%$ clay $(b, c) 1.5 \%$ clay 
ably alters the dynamic asymmetry caused by preferential clay localization inside the epoxy phase. The study of the effect of clay on the phase diagram is in progress. Observation of selected 80/20 samples at lower conversions indicates a self-similar development of the structures identified here (droplet like structures were formed immediately, without the appearance of a bicontinuous structure), at least at the conversion for which SEM observation was possible.

The marked effect of clay on the structure is also obvious in the 70/30 system (Figure 5). In this case, the original structure, consisting of a PCL matrix and closely stacked and partially interconnected epoxy globules, is transformed to a rough bicontinuous structure by the presence of clay. Figure 5 a shows the relatively fine size of the epoxy globules $(<4 \mu \mathrm{m})$ in comparison with those of the analogous $80 / 20$ system (Figure 4a) as a consequence of the higher PCL content. Figure 5b, 5c show that the co-continuous PCL-rich phase contains interconnected epoxy particles, suggesting that the clay-enhanced viscosity of the epoxy (slowing the epoxy dynamics) leads to the dual continuity of the epoxy in both the relatively rough continuous epoxy-rich threads and the interconnected epoxy globules inside the continuous PCL-rich phase. It can be seen that the epoxy globules attached to the continuous epoxy phase are merged incompletely (Figure 5c), which seems to be a consequence of the different degree of curing in the epoxy-rich phase and in the globules formed in the PCL-rich phase [41]. Finally, the fact that the increased clay content does not lead to a continuous epoxy phase as it does in the $80 / 20$ system is apparently a consequence of the high PCL content.

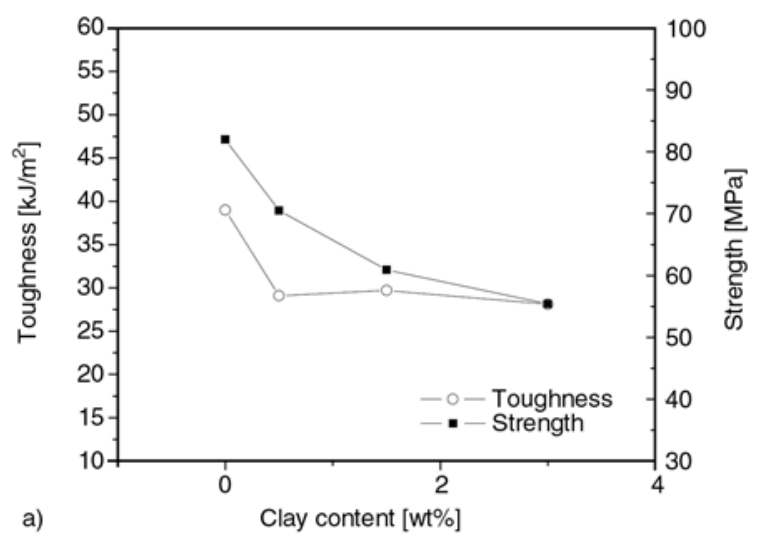

An important feature of all structures containing closely packed epoxy globules (Figures 4a, 4b and 5) is their at least partial interconnection, which is also documented by the fact that the structure was preserved, in spite of the PCL matrix extraction using tetrahydrofuran.

The above results clearly show that the effect of the clay on the dimensions of the PCL inclusions was small at low (subcritical) PCL content, for which phase separation was the expected nucleation and growth (NG) mechanism (i.e., dynamic asymmetry is less important because of the reduced extent of mass transfer). On the other hand, when the PCL content exceeded the critical concentration with expected spinodal decomposition (SD) [40] mechanism, the structure was significantly affected by the dynamic asymmetry [43], and the clay-induced change in this asymmetry led to a phase inversion. Consequently, the effect of the clay was similar to that of an increase in the molecular weight or the content of the epoxy rich phase (i.e., the component influenced by NF).

\subsection{Mechanical properties}

Because of the relatively low level of the mechanical properties of PCL, the goal of this work was to study the potential of NF to tailor the structure and properties at respective PCL concentrations rather than the achievement of highly enhanced mechanical properties of epoxy systems.

In the case the 95/5 epoxy/PCL matrix, Figure 6 clearly shows that best values of the strength and toughness occurred in the sample without added clay, in contrast to the systems with higher PCL contents and the analogous systems with different

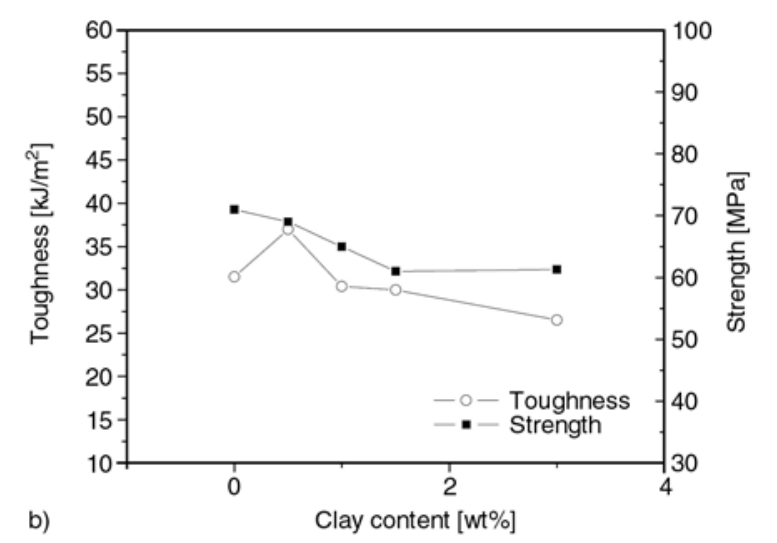

Figure 6. Effect of clay content on strength and toughness of epoxy containing (a) $5 \mathrm{wt} \%$ and (b) $10 \mathrm{wt} \%$ polycaprolactone 
thermoplastic modifiers, which show the synergy of the clay/thermoplastic combination [14-17, 19]. The reduced properties in the presence of clay appear to be a consequence of the lower PCL content (and the resulting lower number of particles), as well as the related increase of the interparticle distance (Figure 1), especially when the low crystallinity of PCL the inclusions $(<5 \%)$ and the resulting significant rubbery character are considered. The lower content of the low-modulus inclusions should increase the strength, which seems to contradict the observed decrease. These results indicate a significant variation effect in the component parameter ratio [44], which is caused by the lower extent of phase separation indicated by both the reduced $T_{\mathrm{g}}$ of the epoxy and the lower PCL inclusion content.

As expected, the refinement of the PCL inclusion size with the addition of clay in the 90/10 epoxy/ PCL blend has a minimal effect on the properties [45]. The simultaneous increase in the toughness with the addition of $0.5 \%$ clay indicates a synergistic effect caused by the clay, which is probably produced by the more favorable ratio of the component parameters (because of both the reinforcement of the epoxy by the clay and the changed composition of both components), as determined by the varying degree of phase separation.

From the dependence of the modulus on the clay content for both 5 and 10\% PCL (Figure 7), it can be seen that the increased clay concentration leads to an expected increase in the modulus as a consequence of the hydrodynamic filler reinforcing effect

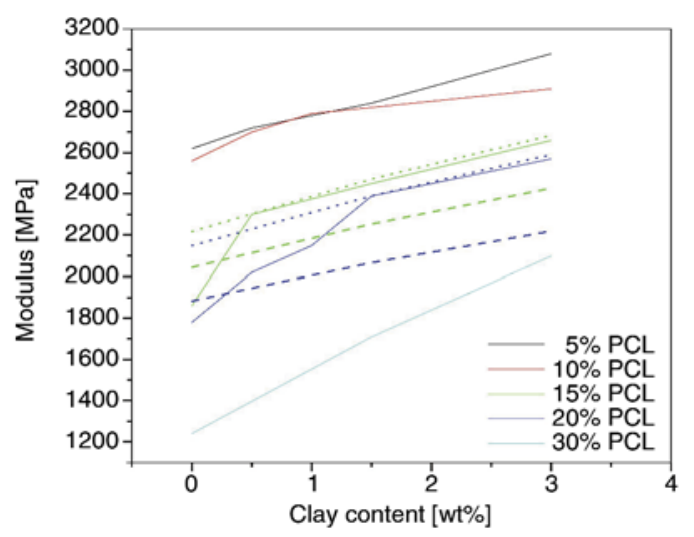

Figure 7. Effect of clay content on modulus of epoxy with various PCL contents. Solid lines represent experimental values. The doted line of the same color represent corresponding Kerner model values and the dashed lines represent values calculated using co-continous model [46].

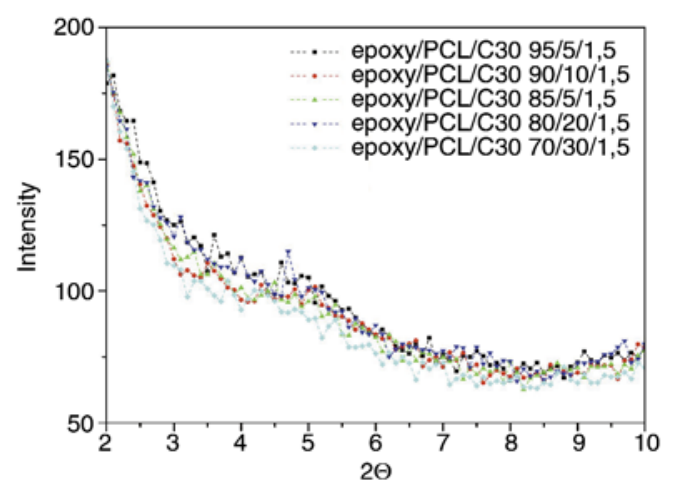

Figure 8. XRD patterns for epoxy/PCL containing 1.5\% clay and their dependence on PCL content

throughout the entire concentration range. This effect apparently exceeds the negative effect of the higher content of residual PCL indicated by the decrease of $T_{\mathrm{g}}$ with the addition of clay (Table 1$)$. The XRD patterns of the samples (Figure 8) indicate a comparable degree of partial exfoliation for all epoxy/PCL matrix compositions (i.e., the reinforcing effect of clay is similar for all systems studied).

With 15 and 20\% PCL, the initial PCL matrix and co-continuous structure transformed to an epoxyrich matrix containing fine PCL domains with the addition of 0.5 and $1.5 \%$ clay for 15 and $20 \%$ PCL, respectively (Figures 3 and 4). This transition produced a radical increase of the strength and toughness of the blend (Figure 9). Interestingly, the best performance was found for an epoxy matrix with PCL inclusions, whereas the structures with a continuous PCL phase exhibited much lower levels of toughness and strength. The reason for this trend is the relatively poor mechanical behavior of PCL (in comparison with other thermoplastics) and the low volume of the PCL matrix between the high content of interconnected epoxy globules (Figure $4 \mathrm{a}$ ) in the $80 / 20$ system without clay. In the case of the 'intermediate' bicontinuous structure with low clay content (Figures $3 b, 4 b$ ), the presence of both phases in the form of rough bulky threads exerted a negative effect on the mechanical properties of the blend. The toughness did not increase with further refinement of the PCL inclusions (in spite of their expected low modulus) because of the independence of the toughness on the particle size within this range [45]. The expected negative effect of clay on the toughness of the epoxy matrix and the changed ratio of the component parameters by the less complete phase separation must also be considered. 

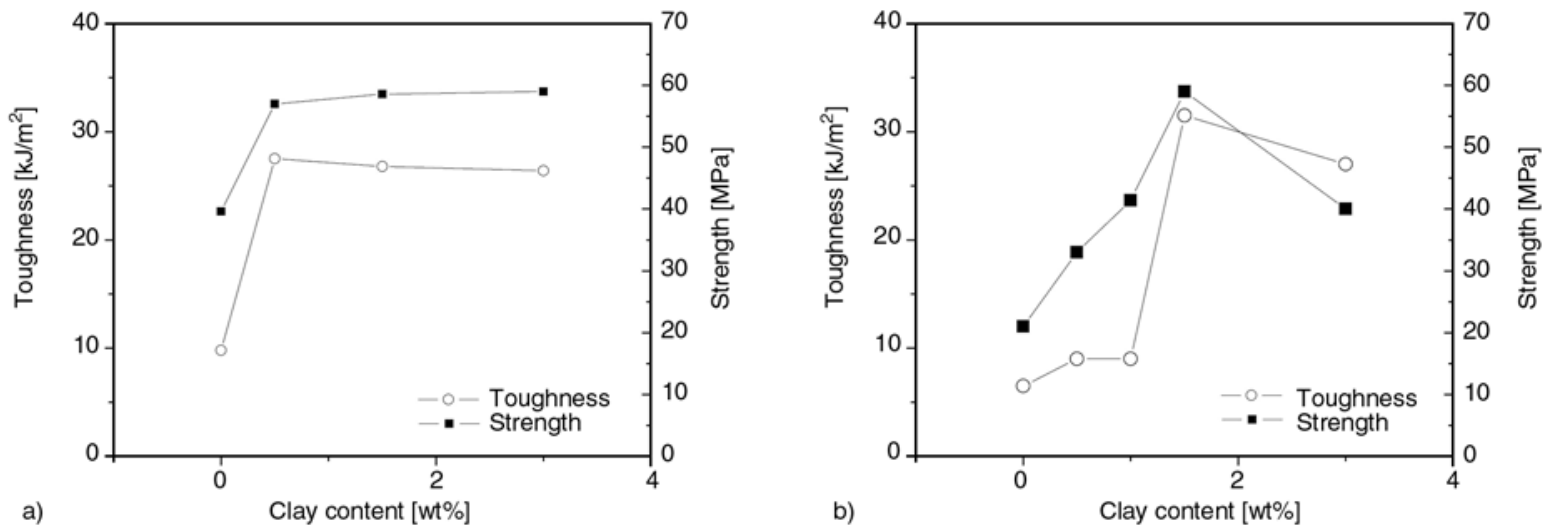

Figure 9. Effect of clay content on strength and toughness of epoxy containing (a) $15 \mathrm{wt} \%$ and (b) $20 \mathrm{wt} \%$ polycaprolactone

Evaluation of the mechanical parameters corresponding to the clay-induced morphological transitions in systems with supercritical PCL contents indicates the possibility that extremely variable properties could be achieved. In the case of low PCL contents, the relatively significant ability to affect the mechanical properties, including the achievement of a synergistic effect with minimal structural changes through a matrix-inclusion structure, indicate the dominant effect of varying the component parameter ratio.

Figure 7 shows that the matrix-inclusion structure (occurring at clay contents greater than 0.5 and $1.5 \%$ for 15 and 20\% PCL, respectively (see Figures 3, 4), exhibits a higher modulus than the system with a co-continuous structure and the same composition. This effect occurs in parallel to the reinforcement of matrix by clay; moreover, this difference in the modulus occurs in spite of the significant change in the PCL crystallinity between the two structures. We have found (Figure $10 \mathrm{XRD}$ ) that an estimated modulus of $50 \mathrm{MPa}$ corresponded to a crystallinity value less than 5\% in the PCL inclusions, whereas the crys-

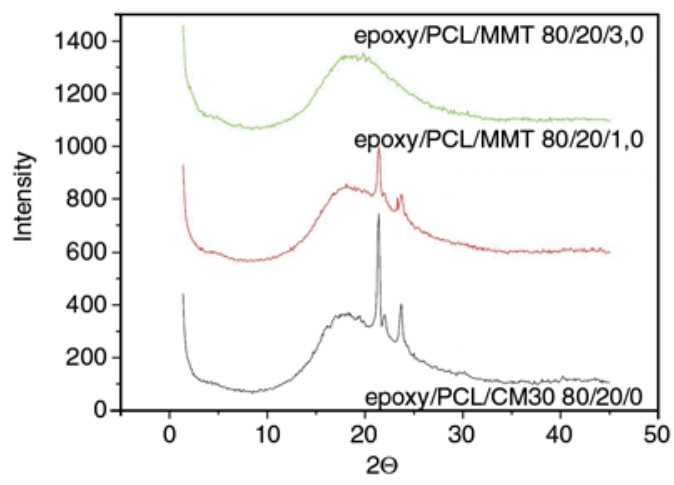

Figure 10. XRD patterns of epoxy/PCL $80 / 20 \mathrm{w} / \mathrm{w}$ system with various clay contents tallinity of the continuous PCL phase was $\sim 50 \%$, corresponding to a modulus of $400 \mathrm{MPa}$. The drastic change in modulus exceeds the effect of the lower crystallinity. This increase corresponds to the wellknown more significant impact [46] of continuous phases on the stiffness of a system, in comparison with that of the matrix-inclusions morphology, as documented by the obvious good correspondence of these experimental results with the approximate values predicted using models for the respective structures [46] (Figure 7) and the above-mentioned corresponding values of the PCL moduli combined with the experimental values of the modulus of the corresponding single epoxy nanocomposite.

In the case of the 70/30 composition, the structure appeared to be unfavorable in all cases (Figures 5a, $5 \mathrm{~b}$ ), and the high content of low-profile PCL corresponded to poor mechanical behavior, which was represented by strength values of $\sim 20 \mathrm{MPa}$ and toughness values of $\sim 10 \mathrm{~kJ} \cdot \mathrm{m}^{-2}$. These poor properties were further confirmed by low $E$ (Figure 7). This significant detrimental effect was produced by the high content of PCL dissolved in the epoxy, which increased with the clay content, as indicated by the significantly reduced $T_{\mathrm{g}}$ (Table 1 ). The presence of interconnected epoxy globules (Figure 5c) inside the co-continuous PCL phase (i.e., the dual continuity of the epoxy phase) had practically no effect on the material properties.

\section{Conclusions}

The effect of organophilized montmorillonite (MMT) on the structure and properties of epoxy containing $5-30 \%$ PCL was significant, especially in the case of supercritical PCL concentration. The radical 
change in morphology observed for 15 and $20 \%$ PCL led to a substantial improvement of the mechanical behavior of the materials. The main reason for this improvement was a shift in the dynamic asymmetry caused by the localization of clay inside the epoxy phase, supporting its continuity. The mechanical behavior was further influenced by changes in the compositions of the coexisting phases because of the reduced degree of phase separation caused by the pinning effect of the clay, as indicated by the lowered $T_{\mathrm{g}}$ of the composites. This effect was more pronounced in the matrix-inclusion structure, for which a synergistic increase in the toughness occurred. The results indicate the potential of clay to tailor the structure and properties of RIPS systems with significant dynamic asymmetry. This fact is further supported by the improvement of mechanical properties, even for the use of PCL, which exhibits a relatively low level of mechanical performance.

\section{Acknowledgements}

This work was supported by the Grant Agency of the Academy of Sciences of the Czech Republic (project No IAA200500904) and Academy of Sciences of the Czech Republic in the frame of the Program supporting an international cooperation (M200500903).

\section{References}

[1] Francis B., Ramaswamy R., Rao V. L., Thomas S.: Toughening of diglycidyl ether of bisphenol-a epoxy resin using poly (ether ether ketone) with pendent ditert-butyl groups. International Journal of Polymeric Materials, 55, 681-702 (2006).

DOI: $10.1080 / 00914030500323326$

[2] Mimura K., Ito H., Fujioka H.: Improvement of thermal and mechanical properties by control of morphologies in PES-modified epoxy resins. Polymer, 41, 44514459 (2000).

DOI: 10.1016/S0032-3861(99)00700-4

[3] Bucknall C. B., Gilbert A. H.: Toughening tetrafunctional epoxy resins using polyetherimide. Polymer, 30, 213-217 (1989).

DOI: 10.1016/0032-3861(89)90107-9

[4] Hourston D. J., Lane J. M.: The toughening of epoxy resins with thermoplastics: 1 . Trifunctional epoxy resinpolyetherimide blends. Polymer, 33, 1379-1383 (1992). DOI: 10.1016/0032-3861(92)90110-I

[5] Oyanguren P. A., Frontini P. M., Williams R. J. J., Vigier G., Pascault J. P.: Reaction-induced phase separation in poly(butylene terephthalate)-epoxy systems: 2. Morphologies generated and resulting properties. Polymer, 37, 3087-3092 (1996). DOI: $10.1016 / 0032-3861(96) 89408-0$
[6] Riew C. K., Kinloch A. J.: Toughened plastics II: Novel approaches in science and engineering. Advances in Chemistry Series 252, American Chemical Society, Washington (1996).

[7] Kelnar I., Khunová V., Kotek J., Kaprálková L.: Effect of clay treatment on structure and mechanical behavior of elastomer-containing polyamide 6 nanocomposite. Polymer, 48, 5336-5339 (2007).

DOI: 10.1016/j.polymer.2007.06.062

[8] Kelnar I., Rotrek1 J., Kotek, J., Kaprálková L.: Effect of montmorillonite modification on the behaviour of polyamide/polystyrene blends. Polymer International, 57, 1281-1286 (2008).

DOI: $10.1002 /$ pi.2475

[9] Alyamac E., Yilmazer U.: Reactive extrusion of poly (ethylene terephthalate)-(ethylene/methyl acrylate/ glycidyl methacrylate)-organoclay nanocomposites. Polymer Composites, 28, 251-258 (2007).

DOI: $10.1002 / p c .20285$

[10] Pascault J-P., Sautereau H., Williams R. J. J., Verdu J.: Thermosetting polymers. Marcel Dekker, New York (2002).

DOI: $10.1201 / 9780203908402$

[11] Kelnar I., Rotrekl J., Kaprálková L., Hromádková J., Strachota A.: Effect of poly(oxyalkylene)amines on structure and properties of epoxide nanocomposites. Journal of Applied Polymer Science, 125, 2755-2763 (2012). DOI: 10.1002/app.36604

[12] Kelnar I., Rotrekl J., Kaprálková L., Hromádková J., Strachota A.: Effect of amine-terminated butadieneacrylonitrile/clay combinations on the structure and properties of epoxy nanocomposites. Journal of Applied Polymer Science, 125, 3477-3483 (2012).

DOI: 10.1002/app.36696

[13] Bakar M., Kostrzewa M., Hausnerova B., Sar K.: Preparation and property evaluation of nanocomposites based on polyurethane-modified epoxy/montmorillonite systems. Advances in Polymer Technology, 29, 237-248 (2010).

DOI: $10.1002 / \mathrm{adv} .20192$

[14] Peng M., Li H., Wu L., Chen Y., Zheng Q., Gu W.: Organically modified layered-silicates facilitate the formation of interconnected structure in the reactioninduced phase separation of epoxy/thermoplastic hybrid nanocomposite. Polymer, 46, 7612-7623 (2005).

DOI: $10.1016 /$ j.polymer.2005.06.013

[15] Zhang J., Xie X.: Influence of addition of silica particles on reaction-induced phase separation and properties of epoxy/PEI blends. Composites Part B: Engineering, 42, 2163-2169 (2011). DOI: $10.1016 /$ j.compositesb.2011.05.013

[16] Peng M., Li D., Chen Y., Zheng Q.: Effect of an organoclay on the reaction-induced phase-separation kinetics and morphology of a poly(ether imide)/epoxy mixture. Journal of Applied Polymer Science, 104, 1205-1214 (2007).

DOI: $10.1002 /$ app.25759 
[17] Mirmohseni A., Zavareh S.: Epoxy/acrylonitrile-butadiene-styrene copolymer/clay ternary nanocomposite as impact toughened epoxy. Journal of Polymer Research, 17, 191-201 (2010).

DOI: $10.1007 / \mathrm{s} 10965-009-9305-8$

[18] Asif A., Leena K., Rao V. L., Ninan K. N.: Hydroxyl terminated poly(ether ether ketone) with pendant methyl group-toughened epoxy clay ternary nanocomposites: Preparation, morphology, and thermomechanical properties. Journal of Applied Polymer Science, 106, 29362946 (2007).

DOI: 10.1002/app.26774

[19] Wu D., Lin D., Zhang J., Zhou W., Zhang M., Zhang Y., Wang D., Lin B.: Selective localization of nanofillers: Effect on morphology and crystallization of PLA/PCL blends. Macromolecular Chemistry and Physics, 212, 613-626 (2011).

DOI: $10.1002 /$ macp. 201000579

[20] Asif A., John B., Rao V. L., Ninan K. N.: Surface morphology, thermomechanical and barrier properties of poly(ether sulfone)-toughened epoxy clay ternary nanocomposites. Polymer International, 59, 986-997 (2010). DOI: $10.1002 /$ pi.2817

[21] Tanaka H., Lovinger A. J., Davis D. D.: Pattern evolution caused by dynamic coupling between wetting and phase separation in binary liquid mixture containing glass particles. Physical Review Letters, 72, 25812584 (1994).

DOI: 10.1103/PhysRevLett.72.2581

[22] Ginzburg V. V., Qiu F., Paniconi M., Peng G., Jasnow D., Balazs A. C.: Simulation of hard particles in a phase-separating binary mixture. Physical Review Letters, 82, 4026-4029 (1999).

DOI: $10.1103 /$ PhysRevLett.82.4026

[23] Suppa D., Kuksenok O., Balazs A. C., Yeomans J. M.: Phase separation of a binary fluid in the presence of immobile particles: A lattice Boltzmann approach. Journal of Chemical Physics, 116, 6305-6310 (2002). DOI: $10.1063 / 1.1460863$

[24] Nesterov A. E., Lipatov Y. S., Horichko V. S., Ignatova T. D.: Effect of filler on kinetics and energy of activation of phase separation in poly(methyl methacrylate)/ poly(vinyl acetate) blend. Macromolecular Chemistry and Physics, 199, 2609-2612 (1998).

DOI: 10.1002/(SICI)1521-3935(19981101)199:11< 2609::AID-MACP2609>3.0.CO;2-Z

[25] Karim A., Douglas J. F., Nisato G., Liu D-W., Amis E. J.: Transient target patterns in phase separating filled polymer blends. Macromolecules, 32, 5917-5924 (1999).

DOI: $10.1021 / \mathrm{ma} 990439 \mathrm{f}$

[26] Araki T., Tanaka H.: Dynamic depletion attraction between colloids suspended in a phase-separating binary liquid mixture. Journal of Physics: Condensed Matter, 20, 072101/1-072101/6 (2008).

DOI: $10.1088 / 0953-8984 / 20 / 7 / 072101$
[27] Yurekli K., Karim A., Amis E. J., Krishnamoorti R.: Influence of layered silicates on the phase-separated morphology of PS-PVME blends. Macromolecules, 36, 7256-7267 (2003).

DOI: $10.1021 / \mathrm{ma} 0207551$

[28] Zhong X., Liu Y., Su H., Zhan G., Yu Y., Gan W.: Enhanced viscoelastic effect of mesoscopic fillers in phase separation. Soft Matter, 7, 3642-3650 (2011). DOI: $10.1039 / \mathrm{c} 0 \mathrm{sm} 01445 \mathrm{a}$

[29] Gharachorlou A., Goharpey F.: Rheologically determined phase behavior of LCST blends in the presence of spherical nanoparticles. Macromolecules, 41, 32763283 (2008).

DOI: $10.1021 / \mathrm{ma} 7020985$

[30] Bao S., Shen S., Liang G., Zhai H., Xu W., He P.: Curing behavior of epoxy resin/tung oil anhydride exfoliated nanocomposite by differential scanning calorimetry. Journal of Applied Polymer Science, 92, 38223829 (2004).

DOI: $10.1002 / a p p .20398$

[31] Tanaka H.: Viscoelastic phase separation. Journal of Physics: Condensed Matter, 12, R207-R264 (2000). DOI: $10.1088 / 0953-8984 / 12 / 15 / 201$

[32] Cicala G., Mamo A., Recca G., Restuccia C. L.: Study on epoxy/thermoplastic blends based on the addition of a novel aromatic block copolymer. Polymer Engineering and Science, 47, 2027-2033 (2007).

DOI: $10.1002 /$ pen.20915

[33] Yeganeh J. K., Goharpey F., Foudazi R.: Rheology and morphology of dynamically asymmetric lcst blends: Polystyrene/poly(vinyl methyl ether). Macromolecules, 43, 8670-8685 (2010).

DOI: $10.1021 / \mathrm{ma} 101421 \mathrm{~s}$

[34] Xia T., Huang Y., Peng X., Li G.: Morphological transition induced by nanoparticles in dynamically asymmetric PS/PVME blends. Macromolecular Chemistry and Physics, 211, 2240-2247 (2010).

DOI: $10.1002 / \mathrm{macp} .201000237$

[35] Zhao L., Zhan G., Yu Y., Tang X., Li S.: Influence of attapulgites on cure-reaction-induced phase separation in epoxy/poly(ether sulfone) blends. Journal of Applied Polymer Science, 108, 953-959 (2008).

DOI: $10.1002 / a p p .27416$

[36] Siddhamali S. K.: Toughening of epoxy/polycaprolactone composites via reaction induced phase separation. Polymer Composites, 21, 846-855 (2000).

DOI: $10.1002 / p c .10239$

[37] Barone L., Carciotto S., Cicala G., Recca A.: Thermomechanical properties of epoxy/poly( $\varepsilon$-caprolactone) blends. Polymer Engineering and Science, 46, 15761582 (2006). DOI: $10.1002 /$ pen.20447

[38] Bershtein V. A., Egorova L. M., Yakushev P. N., Pissis P., Sysel P., Brozova L.: Molecular dynamics in nanostructured polyimide-silica hybrid materials and their thermal stability. Journal of Polymer Science Part B: Polymer Physics, 40, 1056-1069 (2002).

DOI: $10.1002 /$ polb.10162 
[39] Kourkoutsaki T., Logakis E., Kroutilova I., Matejka L., Nedbal J., Pissis P.: Polymer dynamics in rubbery epoxy networks/polyhedral oligomeric silsesquioxanes nanocomposites. Journal of Applied Polymer Science, 113, 2569-2582 (2009).

DOI: $10.1002 /$ app.30225

[40] Chen J-L., Chang F-C.: Temperature-dependent phase behavior in poly( $\varepsilon$-caprolactone)-epoxy blends. Polymer, 42, 2193-2199 (2001).

DOI: 10.1016/S0032-3861(00)00511-5

[41] Vanden Poel G., Goossens S., Goderis B., Groeninckx G.: Reaction induced phase separation in semicrystalline thermoplastic/epoxy resin blends. Polymer, 46, 10758-10771 (2005).

DOI: $10.1016 /$ j.polymer.2005.09.013

[42] Chen J-L., Chang F-C.: Phase separation process in poly( $\varepsilon$-caprolactone)-epoxy blends. Macromolecules, 32, 5348-5356 (1999). DOI: $10.1021 / \mathrm{ma} 9818190$
[43] Zhang Y., Chen F., Shi W., Liang Y., Han C. C.: Layered structure formation in the reaction-induced phase separation of epoxy/polysulfone blends. Polymer, 51, 6030-6036 (2010).

DOI: $10.1016 /$ j.polymer.2010.10.027

[44] Kelnar I., Stephan M., Jakisch L., Fortelný I.: Reactive blending of Nylon 6 and modified poly(styrene-comaleic anhydride); Influence of poly(styrene-co-maleic anhydride) modification by fatty amine onto blend properties. Journal of Applied Polymer Science, 66, 555-562 (1997).

DOI: $10.1002 /(\mathrm{SICI}) 1097-4628(19971017) 66: 3<555:$ : AID-APP17>3.0.CO;2-U

[45] Yee A. F., Du J., Thouless M. D.: Toughening of epoxies. in 'Polymer blends: Performance' (eds.: Paul D. R., Bucknall C. B.) Wiley, New York, 225-267 (2000).

[46] Willemse R. C., Speijer A., Langeraar A. E., Posthuma de Boer A.: Tensile moduli of co-continuous polymer blends. Polymer, 40, 6645-6650 (1999). DOI: $10.1016 / \mathrm{S} 0032-3861(98) 00874-\mathrm{X}$ 